\title{
Transformational Learning in the Workplace
}

\author{
Sarojni Choy \\ Lecture, School of Learning and Professional Learning \\ Queensland University of Technology \\ Victoria Park Road, Kelvin Grove \\ Queensland 4059 \\ Australia \\ Phone: ${ }^{+} 61731383425$ \\ Fax: ${ }^{+} 61731383864$ \\ Email: s.choy@qut.edu.au
}

Acknowledgement: I greatly appreciate the voluntary participation of the learning cohort in the case discussed in this paper. I am grateful to Prof. Brian Delahaye for his assistance with the delivery of the course in the case study and for the research reported in this paper. Prof. Jack Mezirow has generously provided feedback on an early draft of this paper.

Keywords: transformative learning, work integrated learning, learning designs, workplace pedagogy. 


\section{Abstract}

This paper summarises some evidence of transformational learning that influenced changes to practice, processes and the organisational culture in a case study. It is based on a cohort of twelve worker-learners enrolled in a Graduate Certificate in Education (Executive Leadership) course offered by an Australian university (Queensland University of Technology). Data for this paper was drawn from interviews with ten participants, a focus group with six of them, their assessment presentations, and reflective notes of the course facilitators. Also included here are the effects on transformational learning of Taylor's (2007) five elements of workbased learning design, Fuller and Unwins' (2004) features of expansive learning and Billett’s (2001) workplace pedagogies.

Although transformative learning theory remains one of the most popular theories in the field of adult education, studies on fostering transformative learning, particularly in groups and in the workplace remain sparse (Franz, 2005). The case study in this paper contributes to a marginal body of literature on transformational learning by groups of learners in the workplace. 


\section{Introduction}

Transformative learning theory remains one of the most popular theories in the field of adult education. It epitomizes learning where frames of reference (sets of assumptions and expectations) are examined and re-evaluated to make them more “inclusive, discriminating, open, reflective, and emotionally able to change" (Mezirow, 2003, p.58). The theory has attracted numerous research and discussions that continue to expand literature on the conceptual and empirical aspects of Mezirow's $(1991,2000)$ seminal work. To-date much of the existing literature on transformative learning contributes to understandings of the meaning making process and its various phases, the essentiality of critical reflection, and the significance of the socio-cultural and linguistic contexts. A recent review by Taylor (2007) found that within this literature, most of the research studies report on fostering transformative learning mainly in formal higher education settings. Given this focus, more research is needed on fostering transformative learning, particularly in groups and in the workplace. Because transformational learning has potential for productive work outcomes there is need for more research on how to facilitate this approach to learning.

Transformative learning transcends beyond skills acquisition to changes in frames of reference, because individuals and groups step out of their 'habits of mind'. Subsequent changes in perspectives then easily lead to more creative and innovative practices at work. Such changes are also critical for successful work integrated learning with aims for an immediate application and transfer of learning. Fostering transformational learning in the workplace then becomes a means to achieve such 
ends. Like other supportive learning environments, the workplace also needs certain adjustments for transformative learning.

Taylor (2007) identified five elements of workbased learning design to foster transformational learning in the workplace. These elements complement features of expansive learning that Fuller and Unwin (2004) suggest, and harmonise well with workplace pedagogies advocated by Billett (2001). Participation by learners in multiple communities of practice, and engagement in diverse tasks, knowledge bases and experiences are listed as expansive features by Fuller and Unwin (2004).

As the course curriculum was work integrated, the paper appropriately begins with a rationale for work integrated learning to support transformational learning. This section also provides the contextual background for the case study.

\section{Rationale for work integrated learning to support transformational learning}

The workplace provides an authentic learning site to transform and construct vocationally and socially meaningful knowledge and skills (see Brown, 1998; Billett \& Boud, 2001; Billett, 1992, 2004; Hager, 2004; Harris \& Simons, 2006). It offers an environment for learning that is founded on the theory of constructivism (Vygotsky, 1978) because learners make meanings by contextualising the content within the workplace learning environment, its culture, and functions. For transformational learning it is the socio-cultural environment of the workplace that provides the cognitive tools (ideas, theories, and concepts) to establish frames of reference that shape interpretations, meaning schemes and perspectives, and knowledge formation 
(Mezirow, 1991). This implies that work integrated learning (WIL) offers much potential for transformational learning in the workplace, and it facilitates a sociocultural experience which shapes interpretations, meaning schemes and knowledge formation.

Mezirow (1991, p. 75) contends that a clear view of existing meaning schemes and their origins is shaped by "cultural and linguistic codes and social norms and expectations.” Critical reflection assists in discovering the origins of existing meaning schemes. An important step for understanding and appreciating the basis for existing frames of reference, before considering changes for current, as well as, emerging contexts is for learners in the workplace to begin with understanding the influence of the socio-cultural and linguistic contexts that shape existing frames of reference and underpinning assumptions. Changes can be most influential if WIL is pursued by a team of workers because a team forms a critical mass that is more powerful in collectively transforming the organisational perspective and frames of reference. Reflecting, interpreting, challenging, re-interpreting and reviewing for transformational learning in order to enhance organisational performance and work outcomes, is more intensified by teams as opposed to individuals.

\section{Workplace learning designs}

Transformational learning in the workplace necessitates appropriate learning design elements such as those listed by Taylor (2007). The elements include "direct and active learning experiences that engage learners personally and stimulate reflections; use of a variety of medium including online facilities; appropriate pedagogical entry 
points such as disorienting dilemma that present the potential for transformation; and nature and importance of support to foster transformative learning (Taylor, 2007, p. 182-183). In developing the learning design, Taylor (2007) advises academics to pay particular attention to factors that limit transformational learning. He also suggests that rules and sanctions about participation in certain work activities should be openly discussed and if possible, rigid role assignments or unequal distribution of group responsibilities should be avoided. This has particular significance for contested workplace affordances (Billett, 2001). Learning designs also need to place greater emphasis on reflective practice instead of task completion. Finally, healthy relationships between team members are also critical for transformational learning. These elements, when complemented with features of expansive learning that Fuller and Unwin (2004) suggest, and harmonised with workplace pedagogies advocated by Billett (2001), provide an ideal workplace environment for transformational learning.

\section{The Case Study}

A cohort of twelve worker-learners was sponsored by their employer, the Queensland Health and Community Services Workforce Council (Workforce Council), to pursue a Graduate Certificate in Education (Executive Leadership) course offered by an Australian university (Queensland University of Technology). The Workforce Council is a non government organisation with a leadership role in implementing reforms in services for health and community care through training and capacity building of the industry's workforce. The cohort comprised of the Chief Executive Officer, seven middle managers and four administrative staff. The Workforce Council brokers and manages training for capacity building to achieve the agreed deliverables 
for its funding agent (Queensland Government, Australia). The conceptual framework to design and package the course originated from a need to enhance leadership capacity of staff at the Workforce Council, at a time when the whole organisation and industry was undergoing reforms. Appropriately, their learning program was customised to meet, where possible, immediate organisational and individual needs. Four study units were delivered using a blended approach where the content was posted on the university's course website for access through the internet. The study units were: Leadership and Change; Politics of Diversity and Identity; Managing Knowledge in Organisations; Changing Agendas in Leadership.

Self-directed learning was supported with fortnightly face to face consultations at the worksite, and regular emails. The course was completed over a period of four semesters. The learning cohort was divided into three teams, each operating as a community of learners and formed a critical mass to engage in transformational learning to influence changes in their perspectives and organizational processes and systems. The cohort initiated and maintained a learning culture of critical and reflective thinking to challenge existing perspectives and practices, and operate on a continuous improvement cycle. This enabled the learners to step out of their 'habits of mind'.

The WIL curriculum for the cohort was evaluated under a Teaching and Learning grant of the university. Data for this article is drawn from this evaluation. The data set included interviews with ten participants, assessment tasks completed by the learners, and reflective notes of the facilitators. The interviews were audio taped, transcribed 
and coded. The key findings from the interview data were presented to a focus group of six interviewees for verification and discussion.

\section{Evidence of transformational learning}

According to Mezirow (1999) there are eight aspects of transformational learning that individuals demonstrate when their learning is situated within contemporary cultures. Evidence of learning by the cohort at the Workforce Council around these eight aspects is summarised below. Some discussion points apply across more than one aspect in Mezirow’s list.

\section{(i) Seek meanings of experiences}

The first instance where the learners sought meanings of what they were learning was during negotiations about the content of the unit, particularly the assigned readings. Accordingly, the relevance of articles on theories and principles covered in each unit of study was explained to the cohort. A new understanding of the significance of theories and principles made them appreciate these for vocational and occupational relevance. Gradually, the cohort began collating its own list of articles that closely reflected the specific nature of their work and industry. One interviewee explained her experience which was common among the cohort.

I selected something I was curious about, interested in, used my current knowledge and looked for bits that I could plug in. Tried to answer the question “What’s bugging me about this?” I was hooked on certain readings. 
The question "What's bugging me about this?” indicated that learners had already started some critical reflection. To validate meanings for the organisational purposes, members of each community of learners shared their interpretations of the meanings they developed by engaging in active learning and rational discourses. They critically analysed and contested their belief systems, current organisational practices and cultures in light of the new knowledge, understanding and perspectives. This took place mostly during group meetings for the study as well as during staff meetings and professional development activities for the Workforce Council.

During the course of their study, there was strong evidence of communicative learning and rational discourse, and more specifically critical dialectical discourse of the nature described by Mezirow (2003). Communicative learning and critical dialectical discourse exemplify productive reasoning, making learning an intentional part of the business strategy. Communicative learning helps align workers around a common organisational goal and when individual and organisational change are strategically aligned, response to change is hastened (Franz, 2005).

The emphasis on questioning, negotiating and creating shared understanding of alternative ways of knowing reflected collaborative and transformative learning (Cranton, 1996). That is, a group of individuals constructed meaningful knowledge for work functions. Moore (2005, p.81) explains that "Collaborative learning situations are created by carefully designing processes for dialogue in an attempt to minimize power dynamics.” He goes on to list Mezirow’s (1997) ideal conditions for such dialogue as when learners are:

- "allowed full access to information, 
- free from coercion,

- allowed equal opportunity to assume various roles of the discourse,

- encouraged to become critically reflective of assumptions,

- empathic and open to other perspectives,

- willing to listen and to search for common ground of a synthesis of different points of view, and

- willing to make a tentative best judgement to guide action” (Moore, 2005, p. 82).

A group process helped learners validate their interpretations and agree on purposeful meanings. For instance, in one exercise they critically analysed their organisational and stakeholder cultures, their communication styles, the language they used and the underpinning assumptions around these. They found that staff within their organisation often followed procedures as individuals (maintained their occupational habits of mind), without group input or critical reflection. Many discovered their approaches quite disturbing. The team presentation (as part of the assessment tasks) and ensuing discussions facilitated the process of making meaning more holistically with other teams and staff across the organisation, and validating these for organisational and individual functional roles. The strength of collegiality was expressed by one participant.

So this program has been a real eye opener and it's just expanded my understanding of what it means to be in the workplace. I loved the fact that I had a learning team around me who brought different skill sets and different perspectives...You know, people just shared everything they had and we found mechanisms to do it. 
The learners expressed exhilaration with the meanings they co-produced to fit into the context of their operations. The cohort in this case study demonstrated deep learning where they linked new ideas to what they already knew, to derive new and meaningful perspectives. For example, knowledge about the socio-cultural issues with the industry allowed them to assess which of the new leadership strategies they learnt would be more appropriate for the different stakeholders, and for the different situations.

For a while several learners got very excited about the new theories and understandings they gained, and their new perspectives. The 'discomfort' from realising the limitations of their existing frames of reference generated considerable motivation and energy to change things in the workplace. This is similar to transitions. There is general agreement in the literature that transitions involve three phases: separation, transition, and reincorporation. These phases are interrelated and potentially concurrent processes and "transition cannot be completed until all three have taken place" (Bridges 2003, p. 9). Their potential concurrency allows individuals to experience both progression and regression in terms of a sense of 'moving on' through a particular transition. Because of this, they do not have distinct timeframes that signal their beginning or end. Similarly, King (2002) talks about the journey of transformation and the stages that include fear and uncertainty, testing and exploring, affirming and connecting and then finally the new perspective develops. Likewise, McWilliam (2007) writes about unlearning taking place before re-learning can be effective. 
The downside of such enthusiasm with the cohort was that their organisation was not in a position to implement changes at a space that the individuals or the cohort expected. Understandably, there were too many other dynamics that needed planning and resources. One interviewee explained: "If an individual has a new idea, it has to compete with other issues." This view recognises a need to transform perspective for change on process and practice. Changes in personal perspectives without organisational change are not unusual, but joint transformation enhances adaptation (Franz, 2005).

(ii) Engage in deliberate mindful efforts to learn

Mindful learning is the continuous creation of new categories, openness to new information and an awareness and appreciation of multiple perspectives (Langer, 1997). In contrast, mindless learning involves settling for former or existing categories, established practices and distinctions (Mezirow, 1999). Both these types of learning have a place in the workplace.

The cohort was assigned a clear set of responsibilities by their organisation's governing board, and received a substantial amount of government funds to deliver against the reform measures for the health and community services industry. This challenge needed them to develop their leadership capacity and manage the agreed changes for reform. Therefore, learners needed to engage in deliberate mindful efforts to learn in order to change their existing perspectives and frames of reference. This way they could improve services to a very diverse set of stakeholders and end-users by adopting more inclusive and client focused approaches. The learning cohort was 
inspired by the members of their learning community and actively participated in open and trustful rational discourses.

The learning communities met after working hours and during weekends, and operated as a social group to continue open discussions outside the formal work environment. Over time the implicit barriers diminished between those who held less senior positions (eg. administrative staff) and the middle or senior managers in the cohort. An atmosphere of 'equity' in this instance enhanced more mindful learning. The seminar sessions, which formed part of the assessment task, generated several debates and discussions around multiple perspectives and proposed organisational changes which were supported by theories and literature. The discussions focused on what changes are most appropriate, convenient and cost effective for high quality service delivery. Mindful learning increasingly became part of the workplace culture. They did this by applying the process for the Graduate Certificate program to other learning activities, as explained by an interviewee, “They [learners] refer to the new knowledge [from the course] as a framework in meetings.” When workers engage in collective action after establishing collective goals and reaching an agreement collaboratively, change is a lot more likely (Moore, 2005).

(iii) Validate and expand beliefs and understandings

As explained in (i) above, in "Seek meanings of experiences", the cohort validated and expanded its beliefs and understandings through rational discourses with its immediate learning teams, other workers as well as their networks. They contested and extended their beliefs, values and understandings and arrived at common interpretations through consensual validation during the formal discourses such as 
group seminars and symposiums, team and staff meetings, and informal discourses. The feasibility of work integrated learning was also debated and negotiated during these sessions.

Interestingly, the cohort achieved very productive outcomes from their rational discourses largely because the optimal conditions for rational discourse and learning, listed by Mezirow (1996, p. 170), were available in their workplace. That is, the learners had "access to accurate and complete information". During the course they developed skills in accessing the needed information if these were not available at their worksite. For example, the cohort accessed a range of online databases through the university library. The learners were "free from coercion and distorting self deception" because they all operated in an open and trustful environment. The development of trustful relationships (discussed later in this paper) over the period of the course diminished any pre-existing coercion.

The learners were able to reflect on evidence and assess arguments in an objective manner. The fact that the assessment tasks required them to justify their positions and arguments (theoretically and practically), provided a level of objectivity in any conclusions they drew. The second task (written essay) required them to critically reflect on presuppositions and consequences for their functional and organisational roles. As mentioned before, during the presentations, each member of the cohort community had "equal opportunity to challenge, question, refute and reflect, and to hear others do the same”. This did not happen only during the formal learning sessions, but extended to other learning instances (for example, meetings, and professional development activities). By understanding the protocols for and 
significance of rational discourse, they developed skills that were applied not only for the purpose of learning, but also when communicating and negotiating with diverse clients. For example, they began to appreciate the significance of "respecting each other when communicating” and regarding the exchanges as a means of clarifying each other's perspectives. That is, the discourses were not about establishing right from wrong, but to understand one another's perspectives. As the collegial learning relationship began to evolve into more friendly associations, the learners were open to accept informed, objective, and rational consensus. Their engagement in rational discourse also “encouraged critical reflection” to develop more advanced meaning perspectives. As explained by Mezirow (1991), critical thinking challenges existing frames of reference and often causes ‘disorienting dilemmas' which are catalyst for change in perspectives and meanings. This suggests that acknowledgement of a new psychological view does not necessarily lead to change in frames of reference. Unless the new view is valued by the individual and co-workers or actively used, the change may not occur.

The cohort's progress with validating and expanding beliefs and understandings was largely influenced by conditions for discourse facilitated by the gradual change in the internal culture for a more tolerant learning culture and affordances of the Workforce Council. As the cohort progressed through the learning program, its members and other staff in the organisation began to appreciate the value of the transformations in the individual and collective frames of references. This further enhanced openness in communication thereby expanded the beliefs and understandings of the cohort as well as other staff. 
(iv) Accept others as agents with interpretations of their experiences that may prove true or justified

The dynamics within the cohort community was such that they all valued each others' strengths and used them as agents who also had experiences that may support and justify their perspectives. This is explained by one interviewee:

... you had to share your ideas with everyone and then everyone had to share their ideas with you, but I think it’s a much more effective way of processing the information... I loved when everyone was doing their presentations and just hearing the wealth of knowledge in the different people here. Particularly some people who've been in the sector a long time and hearing how they applied those readings and hearing people actually say that reading is crap, or that's not true, because I've got all these years of experience and I've seen that it's not true, or I've seen that it is true. That was really different to when I was in uni because we just chewed the readings up and spat them out again. So just the whole critical analysis process I found really useful and it was great to see other people who have more experience than me and be able to think differently.

This ‘junior’ (administrative) staff accessed and utilised the knowledge and powers of the senior staff (managers) to confirm her interpretations and application of new ideas in her learning team. The presence of the executive director and other senior managers in the cohort provided others in the cohort with an added advantage because they (executive director and other senior managers) had first hand knowledge of what the 
cohort and organisation needed. The executive director and other senior managers became supportive agents.

As well there was huge value in teams working through the organisation so you know from (name of executive director) and managers, to administrative officers and the senior project officers are looking to you because you have studied more recently, you have got lots of expertise in the technology and how to get into things and so really valued as an officer. (Comment form an administrative officer)

Indeed, in many instances the senior managers began to actually mentor some of the fellow learners - something that was a secondary outcome of the program design. During the student seminars, the learners began to note the expert knowledge bases held by individuals and groups. In fact, some started making links, networking and negotiating deals for their work projects during and at recess between the seminars.

In addition to their colleagues, access to academics other than the facilitators, and other university support staff added to the number of agents whose knowledge, expertise and experiences were seen as useful resources. Learners who felt comfortable treating the facilitator as a 'peer' engaged in more frequent and open discussions during the face to face consultations, to openly validate their perspectives and meanings.

(v) Validate contested beliefs and understandings through reflective discourse 
As explained earlier, a cohort approach to learning allowed learners to validate contested beliefs and understandings. As the learning culture within the workplace flourished, learners developed productive reasoning skills to share views, engage in active listening and inquiring others' perspectives. These characteristics are typical in learning organisations (Marsick and Watkins, 1999). The process was facilitated by learning tasks that included critical and reflective discourses required for the assessment tasks. Learners had to critically analyse literature and theories to justify and support their interpretations, claims and transformed positions. This encouraged critical and reflective discourses among the cohort as well as with fellow staff members. Furthermore, the seminars and symposium organised as part of the assessment facilitated the contestation.

The process made me aware that you can only really learn so much as an individual, and that group aspect is really crucial to broadening your own understandings and your own comprehension. Certain issues, particularly, as the change management and the culture materials in the first unit were so broad...that conversational style of learning and sharing ideas and it really gets your thinking going in terms of how to relate it to a real world context.

The seminars were attended by staff other than the cohort members and the symposium also included members of the Workforce Council networks and university academics with expert knowledge. This allowed the learners to engage in reflective discourses with a diverse group of people. 
(vi) Understand the meaning of what is communicated by becoming aware of the assumptions (intent, truthfulness, qualifications) of the person communicating and the truth, appropriateness and authenticity of what is being communicated

During the learning experiences, learners were asked to review and reflect on current organisational thinking, cultures and practices. This coincided with their learning about communication and issues on cultural diversity. It made them more aware of a range of assumptions about their current organisational policies, practices and processes, as well as their personal standpoints. The cohort was challenged to establish how individuals got to have certain perspectives and what shaped the way they formed understandings that then shaped the organisational processes and procedures. This exercise alluded to surprisingly discomforting conclusions and 'embarrassments'. For instance, the very candid and genuine thoughts and recent experiences of a learner who came to Australia as a refugee, (and for whom English was a second language) raised awareness of the sensitivities that others in the cohort had not imagined to be significant. An emotional presentation at the beginning of the course by this learner created the ‘disorienting dilemma' which sparked emotional intelligence capacities of everyone in the cohort. They now recognised first hand, the emotions triggered by their seemingly fair communication process, and faced the 'pain' of someone they actually knew and worked with, who had accessed the services of the Health and Community Services Industry. This single 'critical incidence' set forth a series of conscious critical reflections on several other aspects of their organisational and individual functions, thereby facilitating transformational learning of different magnitudes. 
Similarly, discussions around diversity issues highlighted limitations in approaches to how certain regional networks were engaged. Importantly, two main areas of concern stood out: untested assumptions held by the cohort who had designed and planned actions based on the needs of mainstream client approaches; and the gap between intentional and genuine invitations for Indigenous networks to participate in activities managed by the Workforce Council. Here, the study and de-construction of invitational theories disturbed their existing frames of reference. This not only transformed individual perspectives, but also influenced changes in processes, procedures and protocols for approaching and working with diverse minority groups.

(vii) Make meaning of experiences through acquired frames of reference As discussed earlier, transformations in frames of reference acquired by the learning cohort was critical to making new meanings. In doing this, the learners discovered what they had taken for granted. They developed a habit of critically examining their beliefs, a process that is now constantly re-enforced by members of the cohort. Furthermore, they constantly referred to what they had learnt from other research and literature to challenge their beliefs and assumptions.

(viii) Transform frames of reference by becoming critically reflective The newly developed (during the course of the study) socio-cultural dynamics among the cohort members continues to transform frames of reference and critically reflect on their ideas. Critical and reflective thinking and rational discourses are now regular activities in the organisation, and embedded in its culture. 
I would have to say the big thing at an organisational level is probably the connectedness among colleagues, and the sense that you have been empowered from the process, that you can actually step forward and have the ability to critically analyse certain things and always question work processes. So it's giving us the capacity to work in a continuous improvement manner.

The statements from another interviewee also summarises the views of the cohort.

The units gave me the time to look at out processes, so take a step back form my day to day tasks and look at our processes as a whole and then look for opportunities for improvements. So it's been a very good environment in terms of having that reflection time and reflecting upon what you do. And in terms of action in change, relevant to my level at work, I’ve just looked at certain elements and how their theories can impact upon them...

The examples above illustrate some evidence of transformational learning in the cohort at the Workforce Council. With the recent change in its learning culture, largely facilitated by the study units, it is likely that transformational learning will form a significant part of lifelong learning for the organisation as well as the individuals. Apart from a change in the learning culture other positive consequences of transformative learning such as those reported by Taylor (1997) were also observed. These included increase in self confidence in new roles and relationships, feelings of greater personal power, increased compassion for others, increased creativity, new connections with others, and changes in discourse. 


\section{Elements of learning designs that supported transformational learning}

Of the elements of learning designs identified in a recent review by Taylor (2007), five had particular impact on the cohort's transformational learning at the Workforce Council. These were: subjective relevancy of content; direct and active learning experiences; use of varied medium; trustful relationships; and organisational support to act on new understandings.

\section{Subjective relevancy of content}

While the units for the Graduate Certificate had relevancy to academic discipline domains, the content needed to be subjectively relevant to engage the learning cohort. This is why work integrated learning was critical. Several pieces of the content were jointly reviewed by the academics and the learners to ensure their relevance to the functions of the Workforce Council and its networks. The learners noted literature that had immediate or long term relevancy. These categories (in terms of their currency) influenced the level of transformational learning they experienced. The new knowledge and understanding that were relevant, applicable and immediately usable facilitated the transformation process. Because the new views were widely accepted, valued and validated and where possible actioned, transformational learning influenced explicit changes to policies, procedures, processes and systems in the organisation. 
As cultural outsiders, managing subjective relevancy is not an easy task for academics. Industry contexts continue to evolve making it difficult to maintain currency of changes, especially when one is not part of that industry. Worker-learners who experience the daily movements are in a far better position to verify the level of relevancy in the context of their workplace. Hence the learners were empowered to engage as active co-producers of the boutique curriculum for the course and co-creators of new knowledge that was meaningful to their work context. To optimise outcomes from the course, it was important for the cohort to collectively validate contested beliefs and understandings through reflective discourse.

\section{Direct and active learning experiences}

The design elements for direct and active learning experiences were facilitated by an organisation centred curriculum framework. Under this framework, learning was focused and situated in the context of the learners and their organisational strategic goals. The worker-learners were keen to enhance their performance and that of the Workforce Council so it made sense for them to work with their teams to initiate and manage the transformation. They had common motives and intentions that formed the basis for their meaning making. Biggs (1999) sees this interplay between motives and intentions as the crux of constructivist theory of learning. Andrews (2005) supports this by saying that "motives and intentions do not arise from individuals alone, they are the result of values and belief systems that form across and within social systems that must influence learning through constraining or advancing particular relationships” (p. 3). This gives importance to transformational learning, to not only become aware of ones own frames of reference and perspectives, but also engage with

others in learning to create new meanings and perspectives. As explained earlier in this paper, the cohort did this by operating as a community of learners and constantly 
engaged in discourses with members and other staff across the organisation for collective consensus on new perspectives.

\section{Varied medium}

The use of varied medium to foster transformative learning has attracted recent research attention (Taylor, 2007) largely because they are seen as powerful learning tools. The learning cohort at the Workforce Council had access to varied materials (paper based, digital and online) as well as real and virtual learning spaces. Learners accessed not only the academic literature on the theories of concepts included in the unit content, but also case studies and vignettes, as well as literature from other industries and fields of study.

Transformational learning was further facilitated through the reflective papers prepared for assessment. These reflective pieces allowed learners to record personal views and learning experiences, and transfer some tacit knowledge into explicit knowledge. In doing this, they were able to explore and analyse personal learning journeys and continue developing their leadership capacity. The formation of study circles that met as a formal team during work and as a social group in the evenings and weekends strengthened their relationships, diminished the barriers of communication, and facilitated transformational learning.

\section{Trustful relationship}

A trustful relationship allows learners to share their understandings, question and contest meanings to gain consensual understanding. The learners in the cohort selfselected themselves into three teams. They represented different sections and levels of 
the organisational structure. Each team had administrative personnel, and middle and senior managers. At first there were some tensions about the level of sharing and questioning because those at the lower levels seemed bound by their roles and hierarchical instincts. The course facilitators had to actively and regularly encourage learners, particularly those performing administrative roles to liberate themselves from the boundaries of their functional roles and contribute as intelligent trainee leaders with much to contribute from what they learned in the course. With the learning unit as a common factor, they accepted that each (irrespective of their positions) had the ability to learn and translate the new knowledge and understanding into valuable contributions to the organisation. They shared information, openly debated, questioned and deliberated on new understandings and interpretations, to reach consensus on changes to their frames of reference, values, work practices and processes.

As the learners increasingly engaged in more informal learning during their lunch time meetings and study sessions after working hours, their friendship began to build a more trustful relationship. Relational qualities of 'peer dynamic' relationship (Eisen, 2001) such as trust, non-evaluative feedback, non-hierarchical status, voluntary participation, shared goals and authenticity became more evident. The team members provided good company, encouragement, peer support, and group validation. Many learners, particularly those from the lower levels experienced an increase in self confidence and self esteem. The new relationships increased cross linkages to projects across the organisation and facilitated varying levels of transformation among staff across the organisation. Peer dynamic relationship was further supported by a trusting relationship with their facilitator. Equalization of power between peers and the 
facilitator was developed over a period of time. Baumgartner (2002) advocates this type of equalisation for consensual validation.

The positive and productive relationships also had a downside in that some noncohort members of staff became envious and in instances resented the power of the new knowledge, ideas and proposals for change. There was some resentment towards the critical mass of the cohort and its power in changing frames of reference of others, and in implementing change that some others were not quite ready for. Certain others disliked the newly acquired expertise of administrative staff who began to have greater input into the strategic and operational matters. Evidently, while the transformative changes were perceived as productive and beneficial to the learners and the Workforce Council, these changes challenged the comfort zones of others and created disequilibrium. Where possible, individuals moderated resistance to changes in their frames of reference, a process that was facilitated by a trustful relationship between team members. Some new views were held back temporarily until more convincing information led to clearer understanding that then influenced change to the frames of reference. In situations such as these, senior managers in workplaces need to appreciate discontent, a natural phase of change, and adequately address any issues that may impact on organisational functions when worker-learners introduce changes triggered by new learning.

Institutional support to act on the new understandings

A learning cohort approach to the development of leadership expertise at the Workforce Council formed a critical mass to validate and endorse transformations at work. As a united force, the cohort was able to garner and gain support for change, 
hence secure cooperation and assistance from the whole of the organisation. The senior managers provided guidance to align their learning with organisational imperatives and directions, and to know how to act on the new understandings. This type of explicit guidance is important for fostering transformational learning (Garvett, 2004) because they support levels of instrumental learning.

The cohort at the Workforce Council demonstrated three distinct stages towards transformation. First, the worker-learners who were developing their leadership capacity deconstructed and synthesised existing organisational and environmental cultures, processes and practices. In doing so, they reviewed their own frames of reference. Second, they analysed and contested their findings and frames of reference. Finally, they reconstructed and transformed their frames of reference to lead changes to current and emerging contexts.

\section{Workplace features that supported and facilitated transformational learning}

The learning process and experiences of the cohort were supported by features of expansive learning environment identified by Fuller and Unwin (2004). That is, the learners participated in multiple communities of practice including those external to the organisation (its regional staff, networks and stakeholders). They engaged in diverse tasks, knowledge bases and experiences. Their learning was acknowledged, supported and formally valued as organisational capability. Furthermore, workplace pedagogies, described by Billett (2001), were afforded by the employer and appropriately utilised by the cohort. The pedagogies included questioning and getting explanations, observation and listening, interacting with others, accessing documents 
in the workplace, learning from daily work activities through practice. These pedagogies were supported by workplace affordances that included fortnightly team meetings; internal communication systems (oral, written and electronic); time allocation for group learning; opportunities to solve problems; systemic knowledge of the workplace; shared responsibility for learning and achieving organisational goals; and timely access to assistance from others, including from the organisational liaison person and the academics. Each team met regularly to plan, review and complete their learning activities. As the individuals and the three teams became more confident, they gradually increased their agentic role in seeking and accessing support for learning and transfer in order to implement changes to organisational policy and practice.

\section{Reflections}

The approach to negotiating and developing a boutique curriculum that aligned with the needs of individual and their organisational goals was a new experience for the participants. While there was excitement from most learners, a few had reservations about how a work integrated learning approach to deliver the curriculum would actually function. Many did not feel comfortable with contributing to the curriculum design because they were used to universities dictating all aspects of learning. This was an empowering experience particularly for three middle managers who worked more closely with the academics. When asked to write their learning objectives and to relate the learning content to their work projects for direct and active learning experiences, many learners struggled. Although the Workforce Council was committed to the learning course and provided support for the learners, such support 
was not well thought through before the learners began their studies. Some support mechanisms took time to put in place.

The academics involved in the case study also operated on several assumptions about work integrated learning for the cohort at the Workforce Council. Because these assumptions were not tested, much time was taken up in attending to issues raised by learners at the Workforce Council. These and similar issues raised by another cohort at a different workplace site form the basis of a set of principles for university and industry for work integrated learning (see Delahaye and Choy, 2007; Delahaye \& Choy, 2008). In hindsight, the academics did not allow much time for the two sets of transformations that the individuals were going through: a work integrated learning approach to learning; and transformations created by the course content.

In this case study those who experienced most change were staff whose work projects started and were completed over the period of their study. They included the middle managers and at least two administrative staff. These participants made explicit changes in their approach and influenced their project participants and the final outcomes. The middle managers used their theoretical knowledge acquired from the course to influence decision making and directions through the CEO and the Workforce Council's governing board. The administrative staff engaged in this course felt empowered by the new knowledge because they felt they had something to contribute, even as very ‘junior’ staff.

\section{Summary}


Transformational learning to facilitate reforms in the health and community service industry was imperative for leadership development of the cohort in this case study. The reforms introduced by the funding agency (Queensland Government) needed a more innovative and inclusive approach to training of the workforce to enhance the quality of services. By situating the learning for the cohort in the workplace context, and using a cohort approach that facilitated a community of practice, the trainee leaders experienced and appreciated the significance and power of transformational learning based in the workplace and the power of learning as a community. The learning tasks tested existing assumptions and expectations (habits of mind, meaning perspectives, and mindsets) through reflective thinking, reflective discourses and reasoning that challenged them to change their perspectives. Their new perspectives were more inclusive, discriminating, open and reflective, and acceptable to their colleagues. This appreciation will form an important perspective when they negotiate training to develop the capacity of the health and community service workforce. Their experience in this course will help them negotiate elements of learning designs to support transformational learning and encourage workplaces to make available pedagogies to support worker-learners.

\section{References}

Andrews, C. (2005). A critical reflection on transformational learning practice.

HERSDA 2005 conference proceedings. Retrieved 1/8/07.

Baumgartner, L.M. (2002). Living and learning with HIV/AIDS: Transformational tales continued. Adult Education Quarterly, 53, 44-70.

Biggs, J. (1999). Teaching for quality learning at university. Buckingham, UK: SRHE and Open University Press. 
Billett, S. (1992). Towards a theory of workplace learning. Studies in Continuing Education, 14(2), 143-155.

Billett, S. (2001). Learning in the workplace: Strategies for Effective Practice. Crows Nest: Allen \& Unwin.

Billett, S. (2004). Workplace participatory practice: Conceptualising workplaces as learning environments. Journal of Workplace Learning, 16(6), 312-324.

Billett, S., \& Boud, D. (2001). Participation in and guided engagement at work:

Workplace pedagogic practices. Paper presented at Researching Work and Learning, Second international conference on learning and work, Calgary, Alberta, 26-28 July. Bridges, W. (2003). Managing Transitions (2nd ed.). Cambridge USA: Pereseus Publishing Co.

Brown, B. L. (1998). Applying constructivism in vocational and career education. Information Series No. 378, Columbus: ERIC Clearinghouse on Adult, Career, and Vocational Education, Center on Education and Training for Employment, College of Education, The Ohio State University, (Eric Document Reproduction Service No. ED428298), http://cete.org/acve/majorpubs.asp

Cranton, P. (1996). Types of group learning. New Directions for Adult and Continuing Education, 71, 25-32.

Delahaye, B, and Choy, S. (2007) Using work integrated learning for management development: Some key elements for success. In Proceedings 21st ANZAM Conference, 4-7 December, Sydney, Australia.

Delahaye, B. \& Choy, S. (2008). A learning partnership with a university: Some considerations for industry. Paper presented at the $22^{\text {nd }}$ ANZAM Annual Conference, 2-5 December, Auckland, New Zealand. 
Eisen, M. J. (2001). Peer-based professional development viewed through the lens of transformational learning. In E. W. Taylor, (Ed.)(2007). An update of transformative learning theory: a critical review of the empirical research (1999-2005). International Journal of Lifelong Education, 26 (2) 173-191.

Franz, N. K. (2005). Transformative learning in intraorgainsation partnerships: facilitating personal, joint, and organisational change. Journal of Transformative Education, 3(3), 254-270.

Fuller, A., \& Unwin, L. (2004). Expansive learning environments: integrating organisational and personal development, in Rainbird, H., Fuller, A. and Munro, A. (Eds). Workplace Learning in Context, Routledge, London, pp. 126-44.

Garvett, S. (2004). Action learning and transformative learning in teaching development. In E. W. Taylor, (Ed.) (2007). An update of transformative learning theory: a critical review of the empirical research (1999-2005). International Journal of Lifelong Education, 26 (2), 173-191.

Hager, P. (2004). Conceptions of learning and understanding learning at work. Studies in Continuing Education, 26(1), 3-17.

Harris, R., \& Simons, M. (2006). VET practitioners working with private enterprises: a "third space”? Journal of Workplace Learning, 18(7/8), 478-494.

Harris, R., Simons, M., \& Clayton, B. (2005). Shifting mindsets: The changing work roles of vocational education and training practitioners. Adelaide: NCVER.

King, K.P. (2002). A journey of transformation: A model of educators' learning experiences in educational technology. Paper presented at the Annual Meeting of the Adult Education Research Conference, (43 ${ }^{\text {rd }}$, Raleigh, NC, May 24-26, 2002. Langer, E. (1997). The power of mindful learning. Reading: Addison-Wesley. 
Marsick, V. J., \& Watkins, K.E. (1999). Facilitating learning organisations: making learning count. England: Gower.

McWilliam, E. L. (2005). Unlearning Pedagogy. Journal of Learning Design 1(1), 111.

Mezirow, J. (1991). Transformative dimensions of adult learning. San Francisco: Jossey-Bass.

Mezirow, J. (1996). Contemporary paradigms of learning. Adult Education Quarterly, 46, 158-172.

Mezirow, J. (1997). Transformative learning: Theory to practice. New Directions for Adult and Continuing Education, 74, 5-12.

Mezirow, J. (1999). Transformation theory - Postmodern issues. 1999 AERC

Proceedings. http://www.edst.educ.ubc.ca/aerc/1999/99mezirow.htm. Retrieved 15/6/06.

Mezirow, J. (2000). Learning to think like an adult: Core concepts of adult learning theory. In J. Mezirow \& Associates (Eds.). Learning as transformation: Critical perspectives on a theory in progress. San Francisco: Jossey-Bass.

Mezirow, J. (2003). Transformative learning as discourse. Journal of Transformative Education, 1 (1), 58-63.

Moore, J. (2005). Is higher education ready for transformative learning: A question explored in the study of sustainability. Journal of transformative Education, 3(3), 76 91. Taylor, E.W. (1997). Building upon the theoretical debate: A critical review of the empirical studies of Mezirow’s transformative learning theory. Adult Education Quarterly, 48, 34-60. 
Taylor, E. W. (2007). An update of transformative learning theory: a critical review of the empirical research (1999-2005). International Journal of Lifelong Education, 26(2), 173-191.

Vygotsky, L. (1978). Mind in Society: the development of high psychological processes, Harvard University Press, Cambridge, MA.

Dr Sarojni Choy is a lecturer with the School of Learning and Professional Studies at the Queensland University of Technology. Her professional activities include research and consultancy, teaching and supervision. Sarojni's research interests include: adult and vocational education, workplace learning, and organisational capacity building. 